\title{
How to Integrate ICT with Didactic Learning Approaches
}

\author{
Dr. Eva Cipi \\ University Ismail Qemali of Vlora Albania \\ eva.cipi@univlora.edu.al
}

\section{Doi:10.5901/jesr.2014.v4n1p325}

\begin{abstract}
This paper is focused on studying ICT use in education framework. The purpose is to identify some typical challenges and issues related to didactic teaching in order to discover ICT tools that could be effectively used in didactic teaching. After analyzing traditional didactic approaches and well-known methodologies like constructivism, we will recommend appropriate ICT resources to enhance didactic teaching in specific classroom scenarios.
\end{abstract}

\section{Introduction}

This work is focused on the effectiveness of alternative teaching and delivery modes. One of the key findings (indeed to some extent there is already evidence) in this field will be a better appreciation of the importance of personal intermediation in education, for a host of reasons. These include the communication of values, indications of significance, and the generation of motivation. Ultimately, the education sector will settle in to a new dynamic balance, with an identifiable multimedia strand or stands, as one and only one amongst other strands of educational activity. Constructivism will be special topics discussed here being the dominant research program in science education, and it continues to generate new research and insights. Technological advancement in the field of information and communication technologies (ICT) was rapid during the first decade of the new millennium. The use of computer in the learning process using multimedia and ICT is one of the most exciting developments. The term multimedia means to communicate in more than one way.

Multimedia is the use of several different media e.g. text, audio, graphics, animation, video, and interactivity, to convey information. Educational multimedia is understood to be multimedia which provides learning resources by using a variety of media in an integrated way for the purpose of instruction. The use of multimedia technology has offered an alternative way of delivering instruction. Interactive multimedia learning is a process, rather than a technology, that places new learning potential into the hands of users. Information on the design and use of multimedia characteristics are not available as a coherent body of literature. Educators should have access to appropriate ways to design software packages that will take advantage of multimedia capabilities without losing the focus on the user's needs or the content being presented.

\section{Didactic Learning}

Didactic Learning is based upon four tenets: meaningful learning is more than accumulating knowledge; knowledge and skills are linked; learning requires far transfer, being able to apply principles to a new situation; and cognitive load, transfers between long-term memory and working memory are unlimited (recall), but transfers between working memory and long-term memory (learning) are limited because working memory (seven unique pieces held for 20 seconds) can be easily overloaded [1]. Behaviorists and direct instructors believe knowledge can be transferred, so they divide learning into small chunks from the simple to the complex. Constructivists believe knowledge cannot be transferred, but must be constructed by the individual, so they use open-ended questions to let learners construct their own answers (cognitive constructivism) and group discussions on answers to correct misconceptions (social constructivism). But an instructional approach must only be as complicated as necessary to achieve learning [2].

All learners try to leverage prior learning to complete tasks regardless of the complexity of answers, until the prior learning does not work or they find a better way. Failure to complete tasks does not mean learners are motivated to learn and they can choose not to learn for any reason: not important; too difficult; or differs from their world-view. If the learner does not perceive the material is important, the learner will use memorization, which is easily forgotten. 
Fig.1. Learning process

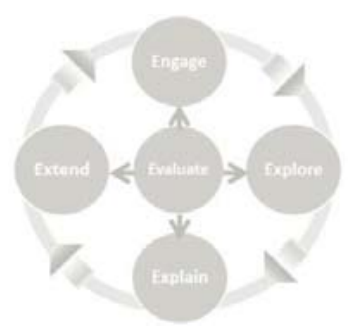

\section{Didactic and Constructivist Methodologies}

Didactic teaching aims to transfer selected knowledge effectively from expert ( in this case is a teacher) to the learner( is a student) Teacher explains how something works or how it is done. He enables students to solve problems on their own. In advance, teacher stimulates students' critical thinking, reflection and creativity. Constructivist learning is focused on helping students construct knowledge by themselves and through interactions with each other. Using this methodology, the teacher help students build knowledge and understanding from within. Another side is that this approach provides opportunities to practice new information. Students' ability is accessed in order to recall and copy a given model.

\subsection{Constructivist model versus Didactic Teaching}

Some educators call for drastic educational reforms leading to skills development to meet the needs of technology - rich 21-st century. Others raise concerns that students today don't accumulate enough 'real' knowledge. They can't recipe poetry or name all the largest rivers in the world, for example.

What is the right approach?

The solution lies in combining both pedagogical methods in different quantities to suit the situation and goals. Developing skills without a reference framework of acquired knowledge is difficult, as is working with pre-selected knowledge without the skills to extend it independently.

\subsection{The teacher's role}

The biggest challenge in a didactic classroom is the teacher's role. The teacher 'owns' the lesson and is responsible for achieving learning objectives.

Table1. The Didactic Classroom

\begin{tabular}{|c|c|}
\hline What the Teacher Does & What the Students Do \\
\hline Identifies desired learning outcomes and selects tasks accordingly & $\begin{array}{l}\text { Follow the teacher's plan and do pre-selected tasks as } \\
\text { required }\end{array}$ \\
\hline $\begin{array}{l}\text { Presents information (for example, how osmosis works in plant } \\
\text { cells or why smoking is bad for you) }\end{array}$ & Read, watch, or listen to new learning content \\
\hline $\begin{array}{l}\text { Models procedures or techniques (for example, how to conduct an } \\
\text { experiment or calculate a percentage) }\end{array}$ & Observe and then copy or imitate \\
\hline Orchestrates activities and manages behaviour & Do as told (or not) \\
\hline Asks questions to check understanding and recall of information & Recall the information they received to answer questions \\
\hline $\begin{array}{l}\text { Selects assessment foci and creates assessments to check } \\
\text { understanding and recall }\end{array}$ & $\begin{array}{l}\text { Prepare for assessment by revising previously learned, pre- } \\
\text { selected information }\end{array}$ \\
\hline $\begin{array}{l}\text { Feeds results and comments on performance back to students } \\
\text { (through marking or verbal comments) }\end{array}$ & Listen to or read feedback and (possibly) try again \\
\hline
\end{tabular}

The teacher's role includes:

- Detailed planning including differentiation by outcome, task, and ability 
- Preparing and/or selecting teaching resources

- Running the lesson as planned

- Preparing, organising, and marking assessments

- Evaluating progress and identifying next teaching steps

- Reporting to parents, the school, and/or the government

Teachers have the same roles within a constructivist pedagogical approach. The main difference is that the students are actively involved in each one as part of their social, emotional, and technical skills development.

\section{Hardware Tools}

How can ICTsupportdidactic teaching and learning tasks?

Projector called also a compujector, teacher can use a data projector, coupled with loudspeakers to share what's on your computer screen with the class. The main benefit is enhanced visibility and audibility for a larrger audience.

A visualisier called digital presenter or digital camera on an arm above a desk and connect it to a data projector to share non digitised items. Main benefits are enhanced visibility of non-digitised content, opportunity to capture still images or videos and storage of images or videos for later referencies or revision.

A USB microscope can be used to share microscopic images with the class. So it is possible to enhance the visibility and have the opportunity to capture still or video images.

Handheld voting device is used to collectresponses from multiple students and link them to presentation software using for example Microsoft PoerPoint Add-in. This device can facilitate direct student involvment in order to allowstudents to control part of presentation and contribute answers. The impact is in increasing accountability, motivation and engagment

Fig. 2. Hardware tools used in didactic learning
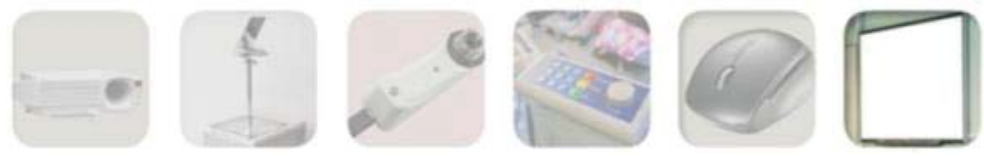

Wireless mouse, keyboard or tablet is used to control the PC from a distance. Main benefit is that device allows teachers to move freely in the class, improving classroom management. Another benefit s that can involve students directly, as they can click or type answers questions. An interactive whiteboard is used to control what's on the screen from projection area. That allows students to interact with the presentation in a fun way. Teachers can move away from their computer. The whiteboard offers multiple users the option to interact with the screen simultaneously, facilitating collaboration and competition.

\section{Software Tools}

Didactic teaching and learning can be supported by different software tools.

\subsection{Multimedia presentation tools}

Tools such as Microsoft PowerPoint are useful for creating slideshows incorporating text, images, audio, video, spreadsheets, and hyperlinks to web, transitions, and movement of components on screen. Through these tools it is possible to combine different media caters students' different learning preferences, or make attractive design draws and retains attention.

\subsection{Interactive tools}

Tools such as Microsoft Mouse Mischief (a PowerPoint add-in to collect students' responses through multiple mice connected to the teacher's computer) allow multiple students to interact with a presentation, even with only one 
classroom computer.

This approach enhances direct student involvement, allows a student to control parts of the presentation and contribute answers. Another opportunity is that this tool increases accountability, motivation and engagement.

\subsection{Productivity tools}

Microsoft Math Worksheet Generator and Microsoft office Suite are useful for creating different documents like letters, worksheets, presentations and spreadsheets. These can be used to create models, visualizations, assessments, or hand-outs, such as worksheets, tests, flowcharts and information sheets. Math and Chemistry add-ins for MS word offer different ways to teach these subjects. It is possible to create professional looking documents, to incorporate multiple media or to produce presentations that can be spell-checked. Adapted and shared electronically with students, colleagues and parents.

Fig 3. Software tools used in the didactic learning process
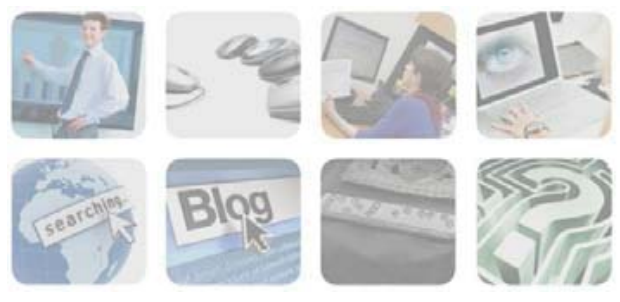

Other tools are grouped in:

Photo and video editing tools,

Research tools,

Communication tools,

Accessibility tools,

Assessments tools,

The technology has had little real impact upon education. Although the personal computer and the internet are old, less than 20 years, information and communication technology (ICT) has changed our life. We live, work and communicate using ICT. The purpose of this paper is to examine the role of technology in education and how to integrate it as an effective $t$

\section{New School Organization - Interactive Technologies}

Courseware. Courseware refers to educational applications within an online lesson (e.g. multiple choice quiz (MCQ), "fillin-the-blank" activity). Interactive demonstrations of the concepts under study; consolidate or test knowledge.

Tutorials. Interactive tutorials mimic situations representative of the actual setting in which learners are able to apply problem-solving skills in accomplishing the tasks as if they had been in the actual environment. Interactive demonstrations of the concepts under study prepare students for real world learning activities; opportunity for refining skills improved; time on task in lectures improved.

Virtual worlds. Virtual worlds refer to interactive simulated 3D virtual spaces in which many users can participate. Currently the most popular virtual worlds in use in education are Second Life. Students freed from the need to be situated within the real environment can learn and receive feedback while interacting within recreated 3D environments such as museums, historical events, crime scenes, hospital wards, chemistry labs.

Virtual labs. A virtual lab is a virtual world within which students can engage specifically in science lab activities such as microscopy or compound synthesis. Aids student preparedness; time on task in real lab setting improved; encourages authentic inquiry (data gathering, synthesis); fosters critical thinking skills.

Virtual field trips. A virtual field trip is a virtual world within which the student takes part in an exploration or expedition such as of a volcano, Stonehenge or a dairy farm. Active, student-centred learning facilitated. Virtual field trips provide project-based learning environments that support exploration and discovery, foster curiosity and raise awareness for issues students are often detached from. 
Simulations. Simulations refer to safe virtual environments that provide users with real-life situations to practice skills. Simulations support exploration otherwise inaccessible because of risk or cost (e.g. flight simulator, combat zone, and earthquake).

\subsection{Emerging Technologies}

In a period of rapid developments in wireless local area networks (WLANs), increasing networking speeds, refined screen technology and software trends, it is difficult to accurately choose and expand upon those new technologies that may one day prove most influential in education. Of the five emerging technologies below: wireless, m-learning and podcasting have been chosen as emergent technologies of not yet widespread applications but for which pilot studies promise more accessible, flexible and active learning experiences. Educational gaming and augmented realities are at earlier stages still in their educational applications and hence only introduced briefly.

Wireless and m-learning. Wireless and m-learning (short for mobile learning) refer to internet technologies that support online teaching and learning applications with access via mobile devices or wireless networks rather than cablebased networks. Wireless and m-learning are not yet established as mainstream practice in higher and further education, but increasingly mobile devices used together with wireless networks will break down further barriers to deliver educational content, enabling multimedia experiences from anywhere and at anytime. There is some dispute over what exactly constitutes a mobile device. Most commonly mobile devices include mobile phones, the hand held devices, personal digital assistants (PDAs) and personal media players (e.g. Apple iPods, iPad, MP3 Players). Mobile devices themselves are increasingly diverging into hybrid devices which integrate multiple functions (e.g. smart phones, which include video capture functions).

Podcasting. Podcasting is the method of distributing multimedia files, such as audio programs or music videos, over the Internet for playback on mobile devices and personal computers. Podcasting supports mobile learning students can listen to a lesson outside the classroom, on a bus on their way home from classes.

Augmented realities. An augmented reality is created by merging virtual images with the real view. In other words graphics, audio, or text is superimposed on a real world environment such as every night on the news meteorologist $\mathrm{s}$ weather map. Augmented realities have been piloted to assist surgeons during operations and soldiers train for war. In education the PDA has been identified as a cost-effective platform for augmented realities.

Educational gaming. Educational games can provide a safe, fun environment for students to learn. Online games immerse students in the material within a competitive or challenging context motivating them more to learn, and encouraging students to learn from their mistakes. Despite these Advantages of using educational gaming has only recently gained recognition by academics as a potentially effective means of facilitating comprehension and knowledge retention. Figure 1 present same of multimedia elements.

\section{Constructivism is an Instructional Strategy}

Involves collaboration between instructors, students and others (community members), tailored to needs and purposes of individual learners, Features active, challenging, authentic and multidisciplinary learning. Constructivism can help students, pursue personal interests and purposes, use and develop his or her abilities, build on his or her prior knowledge and experiences, develop life-long learning. Constructivism encourages instructors to provide for each student's preferred learning style, rate of learning and personal interactions with other learners. Also, it adapts teaching to address students' suppositions and development and assess student learning in context of teaching. At the end, the constructivism shifts emphasis from teaching to learning, individualizes and contextualizes students' learning experiences, helps students develop processes, skills and attitudes.

It considers students' learning styles and is focused on knowledge construction, not reproduction, uses authentic tasks to engage learners, provides for meaningful, problem-based thinking, requires negotiation of meaning and reflection of prior and new knowledge. It extends students beyond content presented to them. To Papert, projecting out our inner feelings and ideas is a key to learning. Expressing ideas makes them tangible and shareable which, in turn, informs, i.e., shapes and sharpens these ideas, and helps us communicate with others through our expressions. The cycle of self-directed learning is an iterative process by which learners invent for themselves the tools and mediations that best support the exploration of what they most care about. Learners, young and old, are "word makers," The difference, is in 3 things:

- In the role such external aids are meant to play at higher levels of a person's development, 
- In the types of external aids, or media, studied (Papert focuses on digital media and computer-based technologies) and more important,

- In the type of initiative the learner takes in the design of her own "objects to think with".

To Papert, knowledge, even in adult experts, remains essentially grounded in contexts, and shaped by uses, and the use of external supports and mediation remains, in his mind, essential to expand the potentials of the human mindcat any level of their development. Papert's constructionism, in other words, is both more situated more pragmatic than Piaget's constructivism.

\section{Case Study: Robot in Classroom}

Using technology, is not particularly complicated and costs are low, as the constructional kit Lego Mind Storms that contain, together with the traditional elements construction (beams bricks mechanisms transmission of the movement, etc.) the RCX, the Brick Special that acts as an interface and / or from "brain electronic ", sensors and software programming.

The RC X is a real programmable computer and can be used to create, build, program real robots and automated construction. A device infrared connected to the computer allows the communication with the RCX. By means of the sensors (of contact, light, temperature), the RCX receives information from the external environment, processes the data and received by the actuators, set the actions that must activate the robot motors, lamps, ring tones, acting, therefore, as expected from the programming. In fact, the robot's behavior is governed by a program running RCX and realized by the software ROBOLAB (which also has a data-logging environment for on-line, graphs, etc.) or NQC.

Fig. 4. RCX Robot software interface

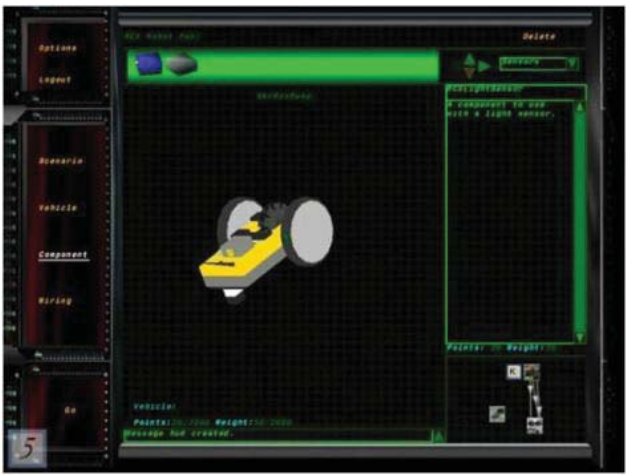

Robotics approach is a learning environment oriented to technological experimentation and scientific conclusions. Every school can start a Lego robotics kit with some involving second classes. The results will be very positive. There will be a significant participation of children, with excellent results in terms of the commitment and the development of skills cognitive and practical-operational. Of particular relevance of education and teaching is the finding that many students with deficiencies in basic instruments and also problems of type behavioral and relationship to express their positive, demonstrating skills and continuity of work, even managing - sometimes with very encouraging results - to identify and developing solutions in hardware (structural changes) and software (need to correct or improve the program) in robotics projects.

\section{Conclusions}

Technology and multimedia will undoubtedly open up new opportunities for educational activity, and new forms of delivery. However, this opportunity will only be exploited as part of the wider scale changes in education and training. In general technology will supplement the existing conventional structures in education, especially over the time scales of the present study.

The powerful position of existing educational institutions and their important non-teaching roles will dampen down 
changes in the overall sector. It may bring about collaborations between commercial educational system developers and educational certification agencies, but this will be to reduce existing rigidities. Technology will certainly enable the opening up of the education system, but it may reduce the opportunities for many people to experience learning in a real institution. It will provide a vehicle for exploring more comprehensively than hitherto the learning process and its ingredients. My aims within this assignment were to look at whether hardware and software tools could be used as a constructivist tools to help enhance young children's knowledge. The evidence would certainly indicate that the model we will show is an excellent tool for use within the classroom. Introducing Roamer into mathematics lessons can provide opportunities for investigation encourage mathematical discussion and generally make mathematics more practical and enjoyable. Other researchers summarized their belief in the use of LOGO in the classroom: We believe that the ability to take responsibility for one's actions, to take risks and see what happens, to experiment and find out for oneself, are all crucial elements for effective learning, that is, learning that can be used flexibly and creatively at a later date. Roamer is a hardware that can help to provide that flexibility.

\section{References}

Cook, D.A., \& McDonald, F.S. (2008). E-Learning: Is there anything special about the "e"? Perspectives in Biology and Medicine, 51(1), 5-21. Baltimore: The Johns Hopkins University Press. Retrieved April 2, 2009

Spiro, R.J., Feltovich, P.J., Jacobson, M.J., \& Coulson, R.L. (1995). Cognitive flexibility, constructivism, and hypertext: Random access instruction for advanced knowledge acquisition in ill-structured domains. Institute for Learning Technologies.

Prenksy, M. (2007). How to Teach With Technology. Emerging Technologies for Learning, 2,40-46. BECTA. Retrieved April 2, 2009

Novak, J.D. (1998). Learning, Creating, and Using Knowledge: Concept Maps as Facilitative Tools in Schools and Corporations. Mahwah, NJ: Erlbaum. Retrieved April 2, 2009

Prenksy, M. (2008). Students as designers and creators of educational computer games. British Journal of Educational Technology, 39(6), 1004-1019. Retrieved April 2, 2009

Jonassen, D.H. (2006). Modeling with technology: Mind tools for conceptual change (3rd rev. ed.). Columbus, OH: Pearson/Prentice Hall.

Rovai, A.P. (2004). A constructivist approach to online college learning. The Internet and Higher Education, 7(2), 79-93. Retrieved April 2, 2009

Caine, R., \& Caine, G. (1991). Making connections: Teaching and the human brain. Alexandria, Virginia: Association for Supervision and Curriculum Development., Retrieved April 2, 2009

Reeves, T. C., \& Jonassen, D. H. (1996). Learning with technology: Using computers as cognitive tools. Jonassen, D. H. (Ed.), Handbook of research for educational communications and technology, 693-719. New York: Simon \& Schuster Macmillan.

Papert, S. (1993) The Children's Machine : Rethinking School in the Age of the Computer. Harvester Wheatsheaf.

Papert, S. (1993) The Children's Machine : Rethinking School in the Age of the Computer. Harvester Wheatsheaf.

Kirschner, P.A., Sweller, J., \& Clark, R.E. (2006). Why minimal guidance during instruction does not work: An analysis of the failure of constructivist, discovery, problem-based, experiential, and inquiry-based teaching. Educational Psychologist, 41( 2), 75-86. Retrieved April 2, 2009 
